\section{Petrarcas læsning}

af forfatter Soren Sorensen, formand i Samradet for de Litterare Selskaber i Danmark.

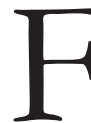
olk der skriver, er folk der læser. Petrarca skrev, Petrarca læste.

Petrarca var meget belæst, han var måske sin tids største kender af romersk litteratur - og af kirkefædrene. Virgil, Horats, Ovid af lyrikerne, Cicero og Seneca blandt filosofferne.

Med udgivelserne af et udvalg af hans italienske digte i 2005, af hans latinske breve i oversættelse og med kommentarer af Eric Jacobsen i 2008 og nu i 2011 af den komplette udgave af Canzoniere har Petrarca fået en position i forhold til danske læsere. Oversættelserne indgår som led $i$ en udbredt interesse for Petrarca overalt i Vesten, renæssancens igangsætter har fået en renæssance. Dette gælder også i forskningen; en række danske forskere har publiceret af- og behandlinger af forskellige sider af hans meget omfattende produktion, både på italiensk og latin.

Hans virkning på skønlitteraturen er også blevet mærkbar hos danske forfattere igen nu, som den har været det siden 1400-tallet i de fleste europæiske lande. For som sagt: folk der skriver, er folk der læser. I og med at man nu igen læser hvad Petrarca skrev - fordi det er blevet lettet eller enkelt sagt muliggjort - mærker man også sporene af hvad han læste.
Det satte sig nemlig tydelige spor $\mathrm{i}$ hans skrifter.

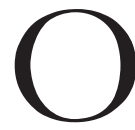
vids Forvandlinger (på dansk ved Otto Steen Due) var i hans italienske lyrik en uudtømmelig kilde. I Canzone XXIII Den sode tid, den livets forste sommer gennemlever digtets jeg, Francesco, en række af

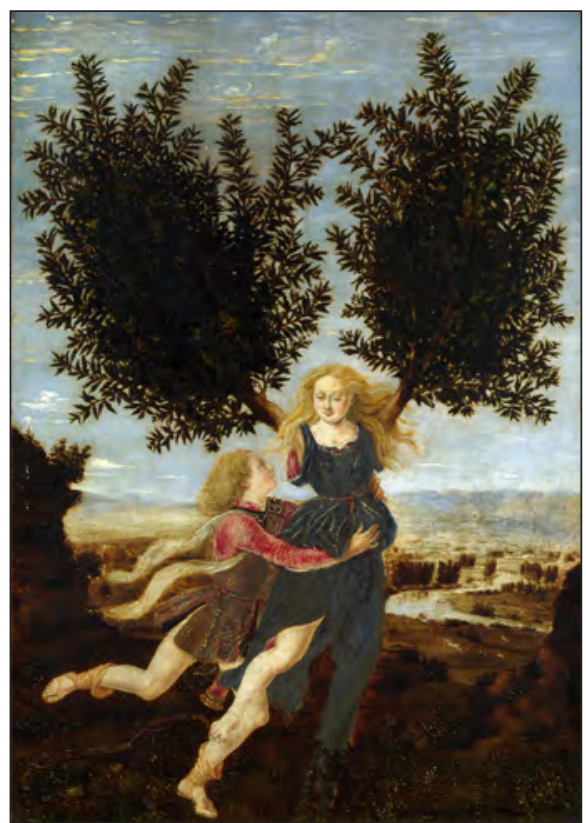

Apollon og Daphne. Idet Apollon fanger hende, forvandles Daphne til et laurbartra. Maleri af Antonio del Pollaiolo, 15. arrbundrede.

de forvandlinger Ovids og den antikke mytologis mytiske skikkelser oplevede: som Daphne blev Francesco til et træ, en laurbær, som Cygnus blev han en svane, en sten blev han til som Battus, en kilde som Byblis, en et ekko som Ekko, nymfen der elskede Narcissus og til slut Aktæon som jagtgudinden Diana omskabte til en hjort og lod ham sønderrive af hans egne hunde. 


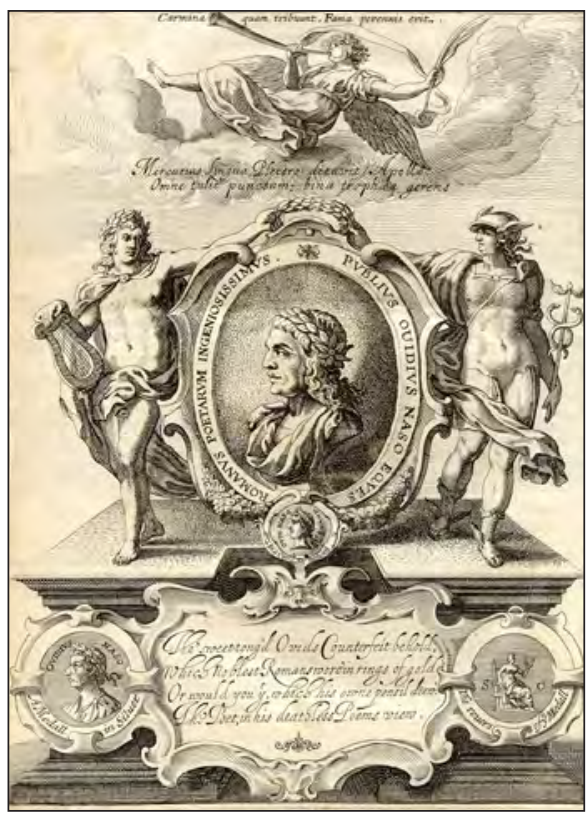

Ovids Metamorfoser $i$ engelsk udgave fra 1632.

Metamorfoser er den latinske digter Ovids 43 f.Kr. - ca. 17 e. Kr.) hovedvark. Det er et heksametrisk epos i femten boger, der genfortaller verdenshistorien med sarlig benblik. pa mytologien og de overnaturlige forvandlinger, som mytologien fortalte om.

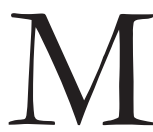
ed Horats går sammenligningerne, spejlingen, på bjerget og kilden, Mont Ventoux og kilden i Vaucluse står i gæld til Horats’ Soracte og Bandusia; lighederne har han direkte fremhævet. I Vilhelm Andersens Horats bind 2 har professoren grundigt studeret hvorledes Petrarca har forvaltet arven fra Horats og spejlet sin egen livshistorie i den romerske klassikers. Dertil kommer at Vilhelm Andersen i sin fremstilling har indlejret værdifulde oversættelser, ikke blot af to centrale sonetter, CXLV og CLIX (Andersen bruger tal fra ældre udgaver der satte numre efter verseform), men også af brudstykker

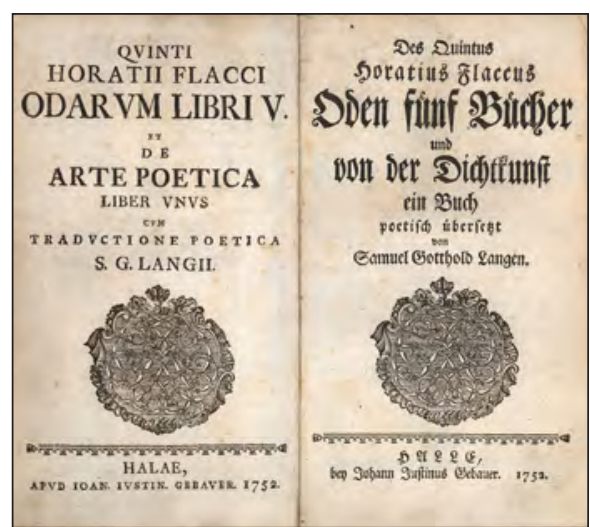

En tysk oversattelse af Horats' Oder og Ars poetica, Halle 1752. Horats, egentlig Quintus Horatius Flaccus (65 f.Kr. -8 f.Kr.), romersk digter. Han blev en af de mest kendte digtere $i$ Rom på Augustus' tid.

fra de latinske heksameterdigte, Epystolae metricae. Også disse digte er ifølge Andersen i deres form Horatslån.

Petrarca sidestillede sig selv med Virgil og Catul og tænkte på sit latinske forfatterskab:

så havde Florens nu haft sin poet,

Verona, Mantua, Arunca ikke bare.

Fra Arunca stammede en satiriker, Lucilius, af hvis produktion meget lidt er bevaret.

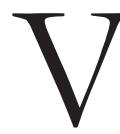

irgil efterlignede Petrarca i endnu højere grad end han lod sig inspirere af Horats. Virgils hyrdedigte, Bucolica, overtog han som mønstre for sin Carmen Bucolicum - en af dem er oversat og kommenteret af Karsten Friis-Jensen i et bidrag til Festskrift til Lene Waage Petersen 2009. Det er Bucolicum Carmens Ekloge IV med titlen Daedalus, et digt om digtergaven, hyrdens lyre hvorpå han spiller så skønt. Ekloge VIII om Petrarcas opbrud fra Vaucluse behandler Minna Skafte Jensen i Avignon 


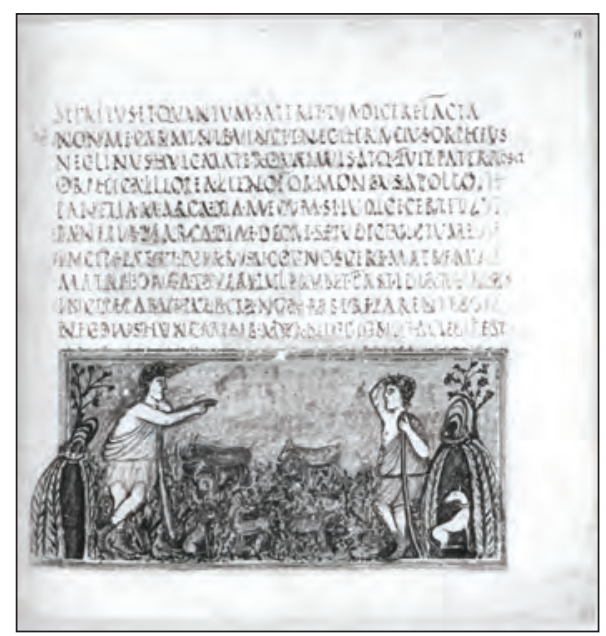

Vergils (70 - 9 f.Kr.) Bucolica, en samling byrdedigte skrevet 39 f.Kr.-38 f.Kr. Antikt manuskript. Hans bovedvark er Æneiden, der er opdelt i 12 sange og inspireret af Homer (de forste seks er inspireret af Odysseen, og de sidste seles af Illiaden).

and Naples: Italy in France, France in Italy in the Fourteenth Century 1997.

Virgils egentlige hovedværk er Æneiden, det store heksameterdigt om Roms tilblivelse som stormagt; det holdt Petrarca meget af og bestemte sig for at skrive et tilsvarende epos om Scipio Africanus, ham der besejrede Carthago og dermed sikrede Rom herredømmet over den kendte verden. Africa er titlen. Værket forblev et fragment - som næsten alt Petrarca skrev - og ingen dansker har mig bekendt beskæftiget sig med det. Derimod findes det i en svensk oversættelse fra 1889 af Henrik Westin.

Selv skrev Petrarca til sin gode ven Giovanni Boccaccio da han var midt i 50'erne at han læste Virgil, Horats, Boëthius og Cicero,

"og jeg læste ikke én men tusinde gange og styrtede ikke igen-

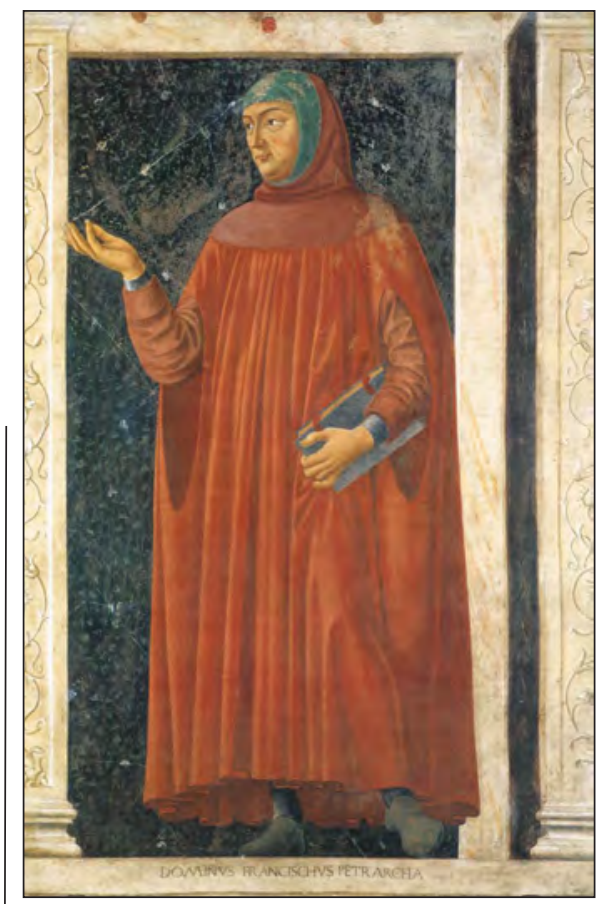

Francesco Petrarca (1304 - 1374), italienske digter og bumanist. Sammen med Dante og Boccaccio har Petrarca varet normsattende for det italienske sprog belt op til nutiden. De var blandt de forste, der skrev på det italienske folkemål - al anden litteratur var på latin, og Petrarca skrev selv mange varker på latin. Han er mest kendt for sine italienske varker, sarligt Canzoniere - en samling karlighedsdigte til Laura.

nem men dvælede ved dem og fordybede mig idem af alle sindets kræfter. Om morgenen slugte jeg hvad jeg om aftenen fordøjede, som dreng inddrak jeg hvad jeg som ældre tyggede drøv på. Dem optog jeg så fortroligt i mig, og de fæstede sig ikke blot i min erindring men i selve hjertet og blev i den grad til ét med min ånd, at selv om jeg ikke skulle læse videre i dem resten af livet, ville de sidde fast fordi de havde slået rødder i sjælens dyb" [Venskabets pris p. 183]. 
A

f uddannelse var Petrarca jurist. Han havde studeret romer-

retten først ved universitetet $\mathrm{i}$

Montpellier, siden ved datidens vigtigste universitet Bologna, et ophold der havde stor betydning for hans udvikling: ikke blot knyttede han livslange venskaber og forbindelser dér, i 1320'erne havde byen status som det vigtigste sted for italiensksproget digtning.

Denne uddannelse - som han foragtede og forkastede - salg af snak, om ikke løgn, kalder han det i et digt - havde dog en vis betydning. Sonetten var som versemål udformet netop af jurister, og sonetten har i sin form lighed med en juridisk argumentation: sådan og sådan forholder det sig - i de første to strofer - og i de sidste to: altså må konklusionen blive den og den. De første strofer, kvartinerne, indledes regelmæssigt med et "som" eller et "når", de sidste, terzinerne med et "således".

Afstanden fra lovstudiet til tekstkritikken, den grundlæggende humanistiske teknik, er kort.

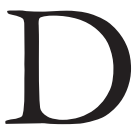
e græske klassikere, Homer, tragediedigterne og filosofferne, kendte han kun fra referaterne hos de latinske forfattere. Han indledte et studium af græsk, men nåede ikke langt, så vidt vi kan se. At han hos sine romerske forfattere havde læst at Homer var en stor digter, så han ikke den fjerneste grund til at betvivle, så han omtaler tit Homer eller Smyrna som ansås for Homers fødeby, og i en af eklogerne, nr. X, i Bucolicum carmen opsøger han ligefrem Homer:

Herfra følger, alt mens jeg tier,

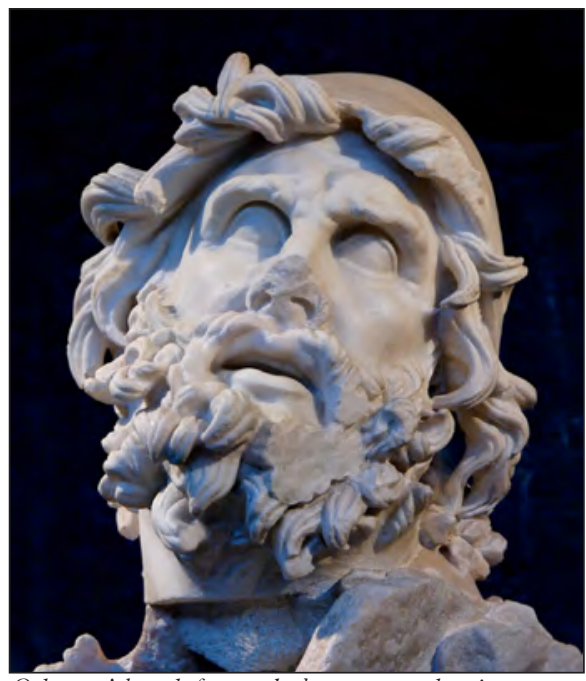

Odysseus' hoved, fra en skulpturgruppe der viser Odysseus der blinder Polyfem. Grask, 2. arh. f.Kr. Homer var den graske digter, som traditionen tillagger de to epos Iliaden og Odysseen og de homeriske bymner.

strande og bugter,

Dybe som fjorde, intetstedsfra høres ekko af sange,

Men når så til marker der toner, og genvinder modet og røsten

Og ordene. Gladere vandre langs dem og ender i Smyrna,

Træffer en blind gammel mand med evner til at se vidtstrakt.

Han hørte jeg kom fra Italien, iled mig derfor i møde,

Rakte mig hånden og indbød den trætte af rejsen til hvile

Hjemme hos sig i skovenes dunkle og skyggede dyb,

Og førte mig grebet af undren gennem de mystiske vildnis.

Sig selv sammenlignede han med Odysseus: han flakkede hverken længere eller videre om end jeg, se Familiares I,1 (Jacobsen 2008 p. 60). 


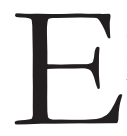

$\mathrm{n}$ morsom illustration af hans læsning af digte fra samtiden finder man i Canzone LXX En ynk jeg ikke ved hvorhen jeg vender. Hver af de fem strofer slutter med et citat, og kommentatorerne har altid gjort sig umage for at bestemme hvor citaterne stammer fra. På den måde bliver canzonen en art dokumentation for hvilke digtere han var fortrolig med. Et vigtigt udgangspunkt for både Dante og Petrarca var den provencalske trubadurlyrik, og i overenstemmelse hermed gengav Petrarca også det første citat på provencalsk:

Drez et razon es qu'ieu chan e m

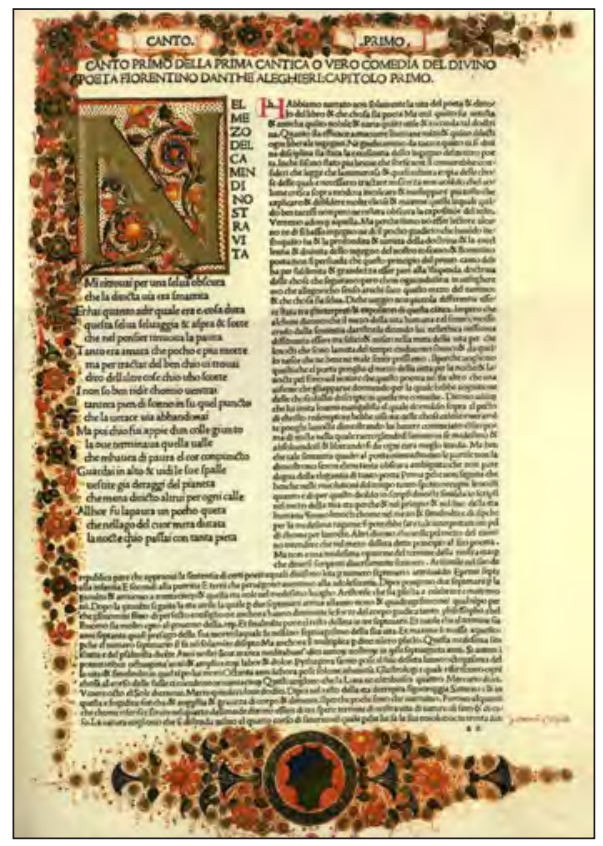

Forste side af en tidlig udgave af Dantes Guddommelige Komedie. Dante Alighieri (1265-1321) var en italiensk. forfatter og politiker. Dante regnes $i$ den europaiske litteraturs bistorie pa linje med Homer, Shakespeare, Goethe og Dostojevskij. Hans hovedvark er Den guddommelige komedie, et episk digt om en rejse gennem helvede, skarsilden og paradiset. demori

[med rette og af gode grunde sang jeg af glæde].

$$
\text { I mange udgaver henføres }
$$

verset til Arnaut Daniel, en digter også Dante lader optræde i purgatoriet kap. 25; senere forskning har påvist at det stammer fra en vis Guillem de SaintGregori. De følgende er alle italienere: Guido Cavalcanti (1250-1300 -), Dante, Cino di Pistoia (1270-1336 eller 1337) og den sidste strofe er så et citat af Petrarca selv. Enkelte af Cavalcantis digte er oversat af J.V. Lind o. 1940, dog ikke dette her. Dante-citatet stammer fra en af de stenhårde" canzoner - rime petrose - den har Johannes Dam oversat til Så skarp i denne sang jeg være vil (i Dante Alighieri: Lyrisk Digtning 1918). Cino di Pistoia var en af Petrarcas venner, i Canzonieren er der flere digte henvendt til Cino som ifølge nogle forskere nærmest kan opfattes som en inspirator i kærlighedslyrik.

Man kunne selvfølgelig undre sig over at han ikke også citerer Boccaccio, men dennes lyriske digtning ligger senere; Petrarca har næppe kendt Boccaccio da han skrev canzone LXX. Til gengæld har Boccaccio skrevet en Petrarcabiografi endnu før de mødte hinanden. Det skete i 1350, og frem til Petrarcas død 24 år senere havde de et nært og oprigtigt venskab. Boccaccio mente ikke at Petrarca nærede samme beundring for Dante som han selv gjorde. Det var sikkert rigtigt nok, i hvert fald gav det anledning til en længere udveksling af tanker om Petrarcas forhold til Dante. Petrarcas redegørelse står at læse i Eric Jacobsens Venskabets 


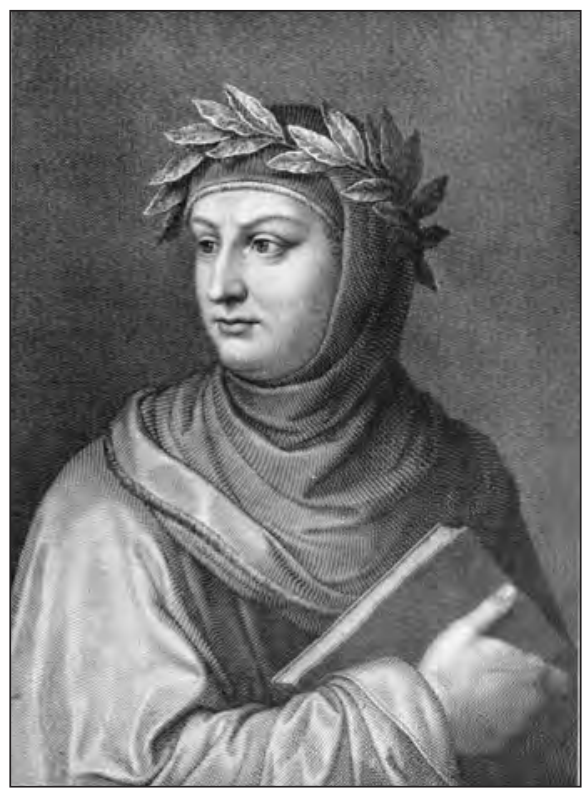

Boccaccio. Stik af Raffaello Sanzio Morghen (1758-1833). Giovanni Boccaccio (1313-1375), italiensk. forfatter og digter, ven af Petrarca, en vigtig renassancehumanist og ophav til en rakke betydelige varker som De mulieribus claris, Decameron og digte på modersmålet, italiensk.

pris side 172 ff. Heri forklarer Petrarca at han ikke havde kastet sig over Den Guddommelige Komedie, fordi han kunne frygte mod mit vidende og vilje kunne blive en blot efterligner.
Nylig er på dansk udkommet Francesco Petrarca:

Canzoniere - eller Sangenes bog. Oversat og kommenteret af Soren Sorensen. 2011. Multivers.

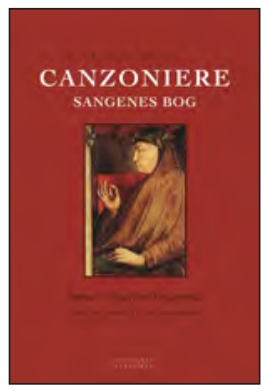

Man kan finde parallelsteder i Canzonieren og komedien, og det er da højst sandsynligt bevidst, når det da ikke skyldes at Dante og han har trukket på de samme forgængere blandt de romerske digtere og kirkefædrene; begge satte jo Virgil højt som man ser: Dante valgte ham til rejsefører i den anden verden, Petrarca efterlignede hans hyrdedigte og hans epos.

Umiddelbart fremstår de som så forskellige åndstyper at den ene, den ældre, ikke vil kunne sige den anden, den yngre, noget. Dante afsluttede middelalderen. Petrarca indledte renæssancen. Petrarca virker moderne. Det gør Dante ikke.

Hvor intet andet navn er anført, er oversættelserne forfatterens. 